\title{
Religion as a Human Right and a Security Threat-Investigating Young Adults' Experiences of Religion in Finland
}

\author{
Pia-Maria Niemi ${ }^{1, *}$, Arto Kallioniemi ${ }^{1}$ and Ratna Ghosh ${ }^{2}$ \\ 1 Department of Educational Sciences, University of Helsinki, Siltavuorenpenger 5, 00170 Helsinki, Finland; \\ arto.j.kallioniemi@helsinki.fi \\ 2 Department of Integrated Studies in Education, McGill University, Montreal, QC H3A 1X1, Canada; \\ ratna.ghosh@mcgill.ca \\ * Correspondence: pia-maria.niemi@helsinki.fi
}

Received: 28 November 2018; Accepted: 8 January 2019; Published: 16 January 2019

\begin{abstract}
The emergence of religiously motivated terrorist attacks and the increasing xenophobia expressed in Europe concern religions in many ways. Questions related to religion also lie at the core of educational aims and practices used to create national cohesion and understanding about different types of values and worldviews. However, despite the topicality of the issue, we have little knowledge about the ways in which young adults experience religions in a secular state. In order to contribute to the discussion regarding the relationships between religion, nationality, security, and education, this study focuses on investigating how politically active young adults experience the role of religions in Finnish society. The qualitative data of this study were collected from young adults (18-30-year-olds) through an online questionnaire distributed through political youth organisations. The content analysis of the responses (altogether 250 respondents) identified five main orientations towards religions. The findings highlight the importance of providing young people with education about different faiths and worldviews for reducing prejudices, especially those related to Islam. The findings also highlight the need to address in education and society the possible but not as self-evident relationship between violence and religion, and to do this more explicitly than is currently done.
\end{abstract}

Keywords: religion; education; security; terrorism; nationalism

\section{Introduction}

The emergence of religiously motivated terrorist attacks in Europe over the last few decades as well as the increasing xenophobia expressed through neonationalist movements in Europe centre around religion in many ways. The terror attacks in particular, carried out in the name of the Islamic State in Iraq and Syria (ISIS) in France, Germany, Belgium, Sweden, Spain, and Finland during 2015 and 2017, have gained extensive international media coverage and made international terrorism of topical concern in Europe. Through these changes, the role of religion has become central both concerning external threats facing the nation from the outside as well as in internal acts of ideologically motivated violence and home-grown terrorism (e.g., Ghosh et al. 2016; Malkki and Sallamaa 2018; Wilner and Dubouloz 2010).

Religion has thus become increasingly associated with questions of security and violence, but the tensions existing in Europe cannot merely be reduced to questions of terrorism. As the forces of globalization (modernisation, urbanisation, secularism, displacement, hi-tech communications, and so on) create tensions for disenfranchised groups, radicalisation is one way of playing out the politics of identity. So, the current turmoil can be identified as part of a larger phenomenon concerning the 
relationship between 'Western', secular values, religious worldviews, and national identifications (Casanova 2009; Miah 2017). Therefore, these issues also lie at the core of the educational aims and practices used to create national cohesion and understanding of different types of values and worldviews. Questions regarding religion have also become central issues in defining the role of education in preventing violent extremism (e.g., Ghosh et al. 2017; Davies 2016; Lynch 2013; Ministry of the Interior 2017; Quartermaine 2016). As these studies point out, in order for education to be effective, it needs to address issues that are relevant in the social surroundings of the students. Therefore, it is central that the measures aiming to counter or prevent the spreading of opinions that support the use of violence are based on an up-to-date understanding of the topical and sensitive issues and tensions within the society concerned.

In order to contribute to the discussion regarding the relationships between religion, security, nationality, and education, the focus of this study is to investigate how politically active young adults experience the role of religion in Finnish society. As a country that has historically had a strong Christian, Evangelic-Lutheran tradition and low number of immigrants, Finland has only recently experienced a notable increase and diversification of religious and cultural traditions within society. However, this increase in diversity has raised many questions and debates about 'Finnishness' as an identity and culture and about the ways in which the society should address different worldviews and traditions. The issue is also topical in discussions concerning educational practices (e.g., Niemi et al. 2014; Itkonen et al. 2015).

This study aims to answer the following research question: How do politically active young adults experience the role of religion in Finnish society? The findings of the empirical investigation are used to provide knowledge about the current societal situation in Finland, as well as to evaluate the role of education and propose the need to discuss these issues in education.

\section{Ideologically Motivated Terrorism in Europe}

In the latest Eurobarometer question about the themes that 'should be discussed as a matter of priority during the electoral campaign for the next European Parliament elections', the themes 'the fight against terrorism' and 'immigration' received the highest scores when the results of the whole Euro area were combined (Eurobarometer 2018, pp. 9-11). These scores show that questions of values and ideas about nationality are urgent in many European countries, including Finland. While we cannot assume from these polls that the phenomena of whether or not the concern for terrorism and immigration are directly related in the minds of the respondents, it is notable that both of these issues create profound changes in societies and that can be considered external threats to the European community as well as for individual European states (see also Eger and Valdez 2015).

Even though the total number of completed or failed terrorist attacks has not increased in Europe within the last few years (226 attempted attacks in 2014 and 205 attempted attacks in 2017), the motivations for these attacks have changed (The Statistics Portal 2018a). Whereas the number of attacks motivated by ethno-nationalist and separatist aims was highest in 2012 and decreased by 2015, there has been a notable increase in the number of arrested 'religiously inspired or jihadist' suspects from 2012 onwards (The Statistics Portal 2018b, 2018c). Even though the number of suspects does not necessarily correspond to the actual acts of terrorism, the increase from 159 religiously inspired or jihadist suspects in 2012 to the highest number of 718 suspects in 2016 is notable (The Statistics Portal 2018c). In comparison, the number of suspects arrested for ethno-nationalist or separatist reasons was highest in 2012 with 257 arrests (The Statistics Portal 2018b). These changes have altered how the threat of terrorism is perceived and discussed in contemporary Europe. In Finland, there has officially been one religiously motivated terrorist attack in 2017, which led to the death of two victims. However, as Malkki and Sallamaa (2018) point out, the actual number of terrorist attacks are hard to define. Based on their analysis of the Finnish context, Malkki and Sallamaa (2018) argue that there have been over 25 deaths from ideologically motivated acts of violence in Finland in the 1990s and early 2000s, but these incidents are not usually labelled acts of terrorism. These researchers also point out that 
there 'is a general preference to not use the term for anything that has happened in Finland' and that this tendency to see terrorism primarily as an external threat is a common way of handling the issue in many countries (Malkki and Sallamaa 2018, p. 871).

These numbers and discussions about the prevalence of ideologically motivated terrorist attacks thus show that, even though the number of attacks in Europe has not significantly changed during the last few years, concern over terrorism in the minds of the public has increased (Europol 2018). One potential reason for this growing concern may be due to the ways in which ideologically motivated terrorism has been framed, primarily as an issue related to violent jihadism (see Malkki and Sallamaa 2018), and thus it is regarded as an external threat that also relates to questions of plurality of values and questions of immigration (see also Casanova 2009). It is these relationships between religion, nationality, and security in the European context that we shall now discuss in more detail.

\section{Religion as an Internal and External Issue of Secular States}

The presence of religiously motivated attacks and security threats-and even more so the potentiality of these threats - have brought religion to the core of security discussions (e.g., Davies 2016; Gearon 2015, 2018; Quartermaine 2016). In addition to ideologies, religions are frequently discussed in relation to migration as often objections or concerns related to immigration are linked to questions about the core values that define a nation-state (e.g., Ben-Porath 2012). In the European context, the 'Western' and 'European' identity has been primarily shaped by the processes of modernisation that emerged in Western Europe in the mid-19th century together with the emergence of secular values (e.g., Taylor 2007; Pérez-Agote 2018).

The secularized European states are thus now facing a time in which religion, on the one hand, has become an increasingly sensitive topic that intertwines with questions of security, terrorism, and immigration, but on the other hand, it also lies at the centre of individual freedom, human rights, and national self-understanding (e.g., Gearon 2018; Casanova 2009). The tensions related to religion are implicit yet implied in the discourses presented by neonationalist far-right movements in most European countries that regard immigration as a threat to the 'traditional, national way of life' (Eger and Valdez 2015, p. 125) and to the economic stability of the country (Eger and Valdez 2015). As the conservative or traditional way of life is defined as such by 'Western' ways of living, so the values and habits that are regarded as different are seen to be a threat and thought to come from outside. As Casanova puts it (Casanova 2009, p. 1059):

It should seem obvious that such a widespread negative view of "religion" as being "intolerant" and conducive to conflict can hardly be grounded empirically in the collective historical experience of European societies in the twentieth century or in the actual personal experience of most contemporary Europeans. It can plausibly be explained, however, as a secular construct that has the function of positively differentiating modern secular Europeans from "the religious other," either from premodern religious Europeans or from contemporary non-European religious people, particularly Muslims.

Thus, despite the diminishing role of traditional religious institutions in European societies, including Finland, questions of religion have again become topical as well as sources of conflict (see McGoldrick 2011). The most common debates concern the visible aspects of religion, such as the right to wear religious garments or symbols in public places or practise religion in public. Despite the fact that the Universal Declaration of Human Rights (United Nations 1948) states that all individuals have the right to 'freedom of thought, conscience and religion' as well as the right to 'manifest his religion or belief in teaching, practice, worship and observance' both in public and private (Article 18), states practice these rights in a large variety of ways. For example, France, Austria, Denmark, and Bulgaria have banned the use of a full-face veil in public places but many countries, such as Finland, have not.

Related to these discussions, Pierik and van der Burg (2014) have proposed two different approaches to reach neutrality when discussing the representations of different faiths and worldviews 
in public spaces: exclusive neutrality refers to the idea of eliminating all religious symbols from public places and spaces in the name of neutrality, whereas an inclusive neutrality can be created by including various types of habits and customs, such as religious ones, in the public sphere of life (see Pierik and van der Burg 2014). As both of these approaches require fundamental discussions about the core values that the society regards as favourable, it is central to note that neither of them is genuinely a 'neutral' approach. It is likewise central to note that secularity is not a neutral way of interpreting the world even though it is sometimes depicted as such. As Casanova (2009) explains, instead of being regarded as a process heading towards something, secularity has become a self-sufficient, unquestionable norm for conducting and perceiving life. Secularity has thus become an ideology in itself, an '-ism', that has many forms (Casanova 2009).

These tensions related to the role of religion in secular states call for multidimensional discussions about the possibility of religions co-existing both alongside different religious traditions and of diverse secular values. Here the role of education becomes central. As Bergdahl and Langmann (2018) bring forward, education about and of values needs to start from the past as the future does not yet exist. However, we claim that, in addition to the past or expected future, educational aims need to be formulated based on the present. In order for education to be successful, it needs to address topical issues and concerns that contemporary society faces. Consequently, in order to better understand the current situation and atmosphere related to religion in Finland, this study focuses on investigating young adults' experiences about the role of religion in Finnish society.

\section{The Role of Education in Combatting and Preventing Polarization}

In relation to the current European and international situations of increasing neonationalism, tensions between religious and secular worldviews, and fear of ideologically motivated terrorism, education has been viewed as one of the most effective ways to prevent violent radicalization and extremism (e.g., Author, various dates). The role of education has, for example, been found to be influential in shaping people's voting behaviour. According to Eger and Valdez (2015, p. 124), having a short formal education increases the likelihood of voting for neonationalist parties and having extended formal education decreases this likelihood. Whereas this example represents a narrow aspect and outcome of education, the deeper question lies in how education prepares children and young people to understand various types of worldviews and societal tensions.

One answer is that education should focus on providing pupils with critical thinking skills and the kinds of knowledge needed to understand the complexities of the world today, including discussions related to different religions and worldviews (e.g., Jackson 2016). Thus, the underlying thought in many educational curricula is that by providing pupils with this knowledge and experience, young people will develop the necessary abilities to interact in the global world and avoid repeating the injustices carried out towards different population groups in the past (Bergdahl and Langmann 2018; Jackson 2016). However, as Bergdahl and Langmann (2018) point out, the teaching of values can no longer start from a conservative viewpoint that expects shared values and aims to transmit these predefined values to future generations. Instead, Bergdahl and Langmann (2018) suggest an approach that highlights the need to have shared values, and to create these through education, while simultaneously recognizing that these values cannot be imposed or retrieved from pre-existing ideals. Here, the role of religious and worldview education becomes prominent in discussing the ways in which questions related to profound values can be approached in the Finnish context. Hence, the next section provides a short overview of the religious education system in Finnish basic education.

\section{Religions in the Finnish Educational Context}

The Evangelical Lutheran Church and its traditions have played a notable part in the formation of Finnish society and the school system until very recent times. Despite declining numbers, over $70 \%$ of Finnish people were still official members of the Evangelical Lutheran Church in 2017. Thus, even though the Finnish Constitution recognizes all religions and worldviews as equals, the historical 
relationship between Christianity and Finnishness as a national identity is unique and has shaped the country's traditions and forms of culture in many ways. This demographic fact is also notable in education, as religious education is a compulsory subject in the Finnish educational system and it is organized according to the official memberships that pupils hold in religious communities. The nature of religious education (henceforth RE) was changed from confessional to nonconfessional in the National Core Curriculum for Basic Education published by the Finnish National Board of Education (FNBE) in 2004.

As the majority of people in Finland are members of the Evangelical Lutheran Church, most RE is carried out with this in mind. For example, $88.6 \%$ of pupils in primary education (ages 7-12) participated in Evangelical Lutheran RE classes, whereas only $2.1 \%$ took part in Islam RE classes in 2016 (Education Statistics Finland 2018a). In secondary education (13-16-year-old pupils), the percentage of pupils participating in Evangelical Lutheran RE lessons was 90.4 while 1.9 took part in Islam RE lessons (Education Statistics Finland 2018b). If pupils do not belong to any religious community, or if they belong to a religious community that does not have a curriculum that the FNBE has validated for teaching it in public schools, these pupils attend secular ethics classes. The number of pupils who participate in secular ethics classes has increased in recent years. In 2016, it was $6.0 \%$ in lower classes and 5.0\% in upper classes (Education Statistics Finland 2018b). However, regardless of the classes attended, all pupils who take part in Finnish basic education should gain a basic understanding and literacy of religions as phenomena (FNBE 2014; see also Moore 2015). According to Moore (2015), religious literacy includes the abilities to recognize the manifestations of religions in their historical and contemporary societal setting. In addition, Wright (2004) has suggested that a religiously literate individual is able to address issues of religion in an 'informed, reflective, sensitive, imaginative and responsible manner' (Wright 2004, p. 225). Both education on religion and secular ethics include teaching and learning about the great world religions, including Islam, Judaism, Christianity, Hinduism, Taoism, and Confucianism (FNBE 2004, 2014). The literacy related to religions and worldviews also includes values related to human dignity and the notion of 'sacred' (FNBE 2014). Both the latest curriculum from 2014 and the previous version from 2004 put special emphasis on developing skills for worldview dialogue and on respect for different ways of thinking and acting (FNBE 2004, 2014).

Even though recent studies have focused on Finnish students' experiences and understanding of religions (e.g., Author, various dates), very few studies have investigated religions from the perspective of age groups that have already completed their compulsory education. However, this type of knowledge about how young adults experience the role of religion in contemporary societies is central for gaining up-to-date knowledge about how religions are perceived and how education should address topical issues in order to prepare pupils for life after school. In order to expand the current understanding regarding young adults' experiences of religion, this study focused on the 18-30-year-old age group that had already completed its compulsory education. In the next section, we present the details of the research design.

\section{Research Design}

This study focused on the viewpoints of young adults who were identified as being politically active because politically active individuals can be assumed to be committed to enhancing certain values and viewpoints. To gain access to politically active young adults, in spring 2018 we sent an online questionnaire to all the official youth organizations of the official political parties currently active in Finland. These are the National Coalition party, the True Finns Party, the Social Democratic Party of Finland, the Left Youth, the Finnish Centre Youth, the Federation of Green Youth and the Young Christian Democrats (not an official translation), and the Swedish Youth of Finland. An introductory e-mail with a link to the survey was sent to the national chairpersons as well as to the local contact persons of all of these youth parties in each municipality in Finland, in order to gain responses from various parts of the country. The questionnaire was primarily aimed at adults between 
18 and 30 years of age as they have the right to vote and they are eligible to join youth organizations. The questionnaire included background questions and nine open-ended questions about the issues in contemporary Finnish society that most pleased or worried the respondents. The questionnaire also included a four-item scale from 1 (completely disagree) to 4 (completely agree). The questionnaire was answered anonymously.

\subsection{Participants}

The online questionnaire was answered in Finnish by 257 people from various parts of the country during spring 2018. The background features of the respondents show that the sample was gained from a heterogeneous group of people representing different worldviews and versatile age groups, genders, fields and levels of work and education. Of the total 250 respondents, 216 people (approx. 87\%) identified themselves as being between the ages of 21 and 29 and altogether 33 people (13\%) identified themselves as either below the age of 18 ( 18 responses) or above 30 (15 responses). Of the total number of respondents, around $40 \%$ identified themselves as female and $58 \%$ as males. Four people did not identify their gender. Likewise, the religious affiliations of the respondents were divided almost equally between people belonging to some religious community (48\%) and people who did not belong to any religious community (52\%). Of the people belonging to a religious community, most $(87 \%)$ identified themselves as members of the Evangelical Lutheran Church or other Christian groups.

The majority of the respondents (32\%) were university students or working people (30\%). The vast majority of the respondents ( $93 \%$ ) were members of a political party. Concerning party membership, the majority of the respondents reported that they belonged to either the National Coalition party $(22 \%)$, the True Finns Party $(23 \%)$ or the Social Democratic Party of Finland (13\%). These three parties represent different political agendas as the National Coalition party is a centre-right party that emphasizes free markets and trade, whereas the Finns Party emphasizes conservative and nationalistic values and the Social Democratic Party is a centre-left party with a focus on the welfare state model. Following from this, it can be concluded that even though the respondents represent, on the one hand, a homogenous group of politically and societally engaged young people, on the other hand, they also represent a group of diverse backgrounds, values, and political orientations.

\subsection{Methods}

The questionnaire included a short introduction that instructed the respondents to write freely about their thoughts and experiences of Finnish society. The first two open-ended questions focusing on Finland were "What are the things that you value most within the society?" and "What are the things that worry you the most within the society?" After these, the questionnaire focused more on questions related to multiculturalism and asked about the respondents' views about the ways in which Finnish society should or should not support different religions and languages. As the final question, the respondents were asked to name which country Finland could use as an example for its immigration policies. In order to answer our main research question ("How do politically active young adults experience the role of religion in the Finnish society?"), this study focuses on analysing the responses given to two open-ended questions: "In what ways should Finnish society support different religions and worldviews?" and, from the opposite perspective, "What types of issues related to religions should society not support?" In both cases, the respondents were also asked to justify their viewpoints. After first analysing the responses to both questions separately, the answers were compared to see if the responses could be identified under the same main categories in both questions.

The written answers were analysed thematically using a data-based content analysis by grouping the answers first into categories according to their theme and then into subgroups (e.g., Cohen et al. 2007). Examples of the themes include the approaches that the responses have towards the role of religion(s) within society, such as an orientation focusing on equality ("all worldviews should be regarded as equal"), on tradition ("Christianity should be supported more than others") or on secularity ("the state should be secular"). After identifying different approaches towards 
religion, these identified orientations were divided into smaller subgroups in order to recognize the differences and similarities within each group. For example, the responses that highlighted the equal treatment of religions and worldviews included both viewpoints that called for the separation of the church and state (an emphasis on secularism) and viewpoints that called for equal state-supported measures to support all religions (an emphasis on religious diversity). In the analysis, particular attention was given to those responses that (a) either regarded the existence of all religions as a threat to society in general or (b) to responses that favoured some religions over others. These were investigated closely as both of these viewpoints represent ideas in which all worldviews are not regarded as equal but that (some) religious worldviews were seen as peculiarities that the state should not support. After the formation of the subgroups, a new set of altogether five main themes, called orientations, were created based on the dimensions that had emerged from the first phase of data analysis. The next section presents these orientations. The selected quotes have been translated from Finnish.

\section{Findings}

The total number of comments related to the two main questions regarding how different religions and worldviews (A) should be supported by society and (B) should not be supported in the society gained over 300 responses in the survey. Of the responses, 168 comments were given as a response to question A and 138 responses to question B. As an outcome of the data-based content analysis, five different types of orientations towards the role of religion and worldviews were identified in Finnish society. Subsequently, a total of five main orientations were created and, based on their primary emphasis, they were labelled "Positive-neutral orientation", "Negative-neutral orientation", "Secularist orientation", "Security orientation", and "Cultural heritage orientation". In the following sections, we describe the main contents of each of the categories and provide examples of the common issues mentioned in each theme. The presented quotes are numbered for clarity.

\subsection{Positive-Neutral Orientation}

The positive-neutral orientation includes experiences and viewpoints that approach religion from a perspective that highlights the individual's right to practise and openly endorse different kinds of religions and worldviews in Finnish society. These viewpoints were justified from a human rights perspective and endorsed the need for society to be equal towards different types of worldviews (see also Pierik and van der Burg 2014). As the excerpts below suggest, the approaches in positive-neutral orientation consider worldviews to be the personal right of an individual, but they also call for the state's active input in supporting this right. The ideas highlighted in the following examples about religious freedom were mentioned in over 80 responses:

[1] There should be space to practise different religions and worldviews in society as long as they are not against the Finnish law or otherwise break the general concept of justice.

[2] [There should be] possibilities to practise and express one's own [world]views without being judged.

[3] In all possible ways both the positive and negative right to religion [should be supported]!

[4] No one's rights to practise their own religion or to use their own language should be restricted because of any conviction, ideology, or fear.

As the excerpts show, these approaches call for equal opportunities for individuals to openly express different religions and worldviews without being judged or discriminated against (quotes 1,2 , and 3). However, in addition to providing opportunities to practise religions, some of the comments categorized as having a positive-neutral orientation call for the state's active role in promoting knowledge about religions. Such measures could include actively reducing prejudices about religions in society (quote 5), providing everyone with basic knowledge and literacy about religions and worldviews (quote 6), or increasing the teaching about religions in schools (quote 7). 
[5] The freedom of religion in Finland is a good thing but more effort needs to be put into it. Of course, Muslims have been denigrated as terrorists, but this should not influence the life of individuals in any ways.

[6] Everyone should be taught basic knowledge about all religions and worldviews.

[7] Teaching [about religions] should be broadened.

The positive-neutral approach also emerged from the responses to question B ("In what ways should religions and worldviews not be supported?") through responses that could be characterized as opposing segregation. According to these viewpoints, society should not enhance or support any kinds of practices or approaches that encouraged discrimination or segregation within society. The following excerpts highlight the importance of education, both as social interaction and as an institution, in preventing prejudices and segregation in society:

[8] Anger and racism [should not be supported]. Using religion to scare people, for example, some people have very negative attitudes towards Islam.

[9] A higher education degree should be required from religious leaders (imams, priest, rabbis, and so on) and ecumenical training [of the leaders] should be increased.

[10] Daycares and schools for immigrants [should not be supported] in order to get them integrated into our culture and community as much as possible.

Whereas quotes 8 and 9 highlight education as important to increase knowledge and provide academic discussions about religions in society, quote 10 introduces the socialising aspect of schools by arguing that the creation of separate schools for immigrants should be avoided in order to help integrate immigrants into Finnish society. Similar types of calls for integrative practices were provided in other comments as well.

The quotes categorized as having a "positive-neutral orientation" thus start from the viewpoint that religions, in themselves, are either neutral or positive elements of the social life and that they need to be allowed open expression. However, as in quote 1, these approaches consider the secular legislation of Finland to be the normative framework to which also religions need to be submissive. These viewpoints show a positive attitude towards the existence and co-existence of different religions and worldviews in society. The "negative-neutral approach" that is presented next also emphasizes equality but from different starting points.

\subsection{Negative-Neutral Orientation}

As in the previously described positive-neutral approach, the responses in the negative-neutral orientation also emphasize the freedom of religion and worldviews but, instead of focusing on supportive practices, the viewpoints in this orientation focus on reducing unequal discriminatory practices related to religions and worldviews. Thus, the word negative here does not refer to negative approaches towards religion but rather to negative forms of freedom of religion, such as 'freedom from' participating in religious practices against one's personal convictions (see also Pierik and van der Burg 2014). A common feature of the responses in this category is the emphasis placed on nonreligious worldviews and, related to this, the ways in which religions and worldviews should be discussed in schools. The following excerpts 11,12 , and 13 are used as examples to summarize the main arguments presented in the negative-neutral approach:

[11] All religions should have equal positions [in society] as long as they do not harm other people. None of the religions should be part of the state and views based on religion should not be regarded as important as scientifically studied facts when it comes to political decision-making.

[12] Equal treatment regarding one's religion or conviction, the freedom of religion also protects nonreligious people and it includes the right to privacy, which means the right to not bring forward one's religious or nonreligious conviction ... 
[13] A neutral society that allows [the existence of] religions in it. Having dialogues between worldviews is an important philosophical discussion so it needs to be encouraged.

As the approaches depicted in excerpts 11,12, and 13 suggest, the negative-neutral orientation does not oppose the existence of religions in society, but rather than focusing on the advancement of religions in society, this approach focuses on the negative aspect of the freedom of religion and on the recognition of nonreligious worldviews as the fundamental rights of all people. Related to this, a total of 29 responses mentioned the need to change the way in which religious and worldview education is provided in schools. These comments called for the renewal of the current religious and worldview education system in which students are taught in different classes according to their memberships in religious communities (see quote 14 below). The main rationale for this renewal was religious freedom, as described by quote 15 , which not only focuses on religious education classes but on school practices in general.

[14] Religious education in basic education could be changed from a nonconfessional format to a general subject on worldviews.

[15] Everyone should have the right to believe or not believe. This includes children under the age of 18 , so they should not be forced to study their parents' religion in schools or be made to participate in religious events (Christmas church visits, morning assemblies) that follow the religion of their parents. Religion should be a private matter.

The comments concerning education (in the negative-neutral orientation) thus emphasize the need to provide the same education for all students and, according to the responses, this should be based either on teachings about different world religions, or about ethics, or both. In addition to religious education classes, the responses in the negative-neutral orientation called for equal practice in the ways in which different faith communities and worldview traditions are presented in schools outside the individual lessons. However, as opposed to the secularist orientation, which is discussed next, the secularist-neutral orientation does not call for the elimination of religious representations, either from society at large or from schools.

\subsection{Secularist Orientation}

Unlike the previously described positive-neutral or negative-neutral orientations, the secularist orientation consists of viewpoints that call for the clear separation of (the Evangelical Lutheran) Church and state (see excerpts 16 and 17). Excerpts 16 and 17 also serve as example quotes of over ten instances that mentioned the need to terminate the taxation rights that currently the Evangelical Lutheran and Orthodox Churches in Finland have.

[16] Everything should be kept separate from the state. All [worldview communities] should have the same right to collect taxes.

[17] The Church should be separated from the state, all religions should have equal positions. The worldviews of nonreligious people should be more respected, being seen as an active choice, not as a lack of something.

Related to the need to clearly separate religious and secular activities in society, the viewpoints in the secularist orientation regard religion and worldviews as private matters that society should not interfere with or support in any way. According to the secularist orientation, along with matters like taxation that the state should not support, the facilities of religious communities, including the building of churches or mosques (excerpt 18 and 19), should not be supported either, or as excerpt 20 puts it: "nothing at all" should be supported.

[18] The society should not] build churches or mosques for religions.

[19] The spaces and costs that come from the activities of religious communities. The communities should pay for these themselves. 
[20] Nothing at all should be [supported]. [Religions are] a completely pointless expenditure.

However, as the following excerpts 21 and 22 show, the secularist orientation entails two notably different types of approaches towards religion: one that highlights the separation between state issues and private issues, such as worldviews, and another viewpoint that strongly opposes or is even hostile towards religious worldviews:

[21] It is not the job of society to take into account people's different worldviews.

[22] Religions should not be favoured or supported under any circumstances; on the contrary, they should be eliminated.

Related to this latter type of opposition or hostility towards religious ideas, an important category of its own that emerged from the data was concerning ideological radicalization and extremism. The viewpoints related to this category are discussed next.

\subsection{Security Orientation}

The orientation focusing on security emerged as a separate category because several comments throughout the data pointed out that the state should not support "extremist movements" or accept violent or illegal actions. Whereas most of the responses did not clearly define what they meant by extremist thinking or extremist movements, the responses related to religion, and many of them associated extremist thinking with illegal actions that violated either Finnish laws, human rights, or individual freedom of choice. As the following excerpts 23-27 indicate, the definition of extremist movements culminated in questions of violence that, regardless of their justifications, were regarded as something that society needs to condemn and oppose:

[23] I don't consider it appropriate for society to support such religions that would act or teach contrary to the laws and norms of that society.

[24] Society should not support] Practices that violate human rights, prohibit the realization of the rights of other people, or otherwise harm others than themselves. Doctors, for example, should not be able to refuse to carry out abortions, as allowing this would jeopardize women's rights to make decisions regarding their own bodies.

[25] There should be freedom of religion in Finland as long as [a person's] worldview is not harmful to society or does not create illegal actions or limit the freedom of religion and of expression for others.

[26] Having freedom from injury is the right of every human; people cannot be abused, slaughtered or harmed for the sake of another person's religion or worldview.

[27] Crimes, inequality and other things that [are based on or go against] religions should be clearly denied.

In addition to these general features, some responses mentioned the practices of particular faith communities as extremist and as features that needed to be opposed. Examples of these were religious circumcisions, which was mentioned twice, and the use of the halal method for animal slaughtering. Most responses mentioning ideological extremism directly referred to Islam. However, as the following excerpts show, most of the responses did not specify what aspects of Islam they considered extremist. Instead, these comments represent general viewpoints about Islam as a violent ideology (excerpts 28 and 29) or refer to radicalized interpretations of Islam as a threat (excerpts 30-32):

[28] The Islamic way of thinking should not be supported as it is an extremely dangerous and radical way of thinking.

[29] I would forbid violent religions, such as Islam.

[30] [Society] should use all measures possible to prevent any aims in which Islamists or other fundamentalist religious movements that originate from Third World countries may try to interfere with legislation. 
[31] Nothing related to religions that clearly encourages criminal activities should be supported. This goes for all religions, but in Finland special consideration needs to be given to preventing radical interpretations of Islam from spreading.

[32] Jihadism is a threat.

[33] Anything that goes against human rights should not be supported when it comes to religions; on the contrary, it needs to be prevented, regardless of the religion. I am more aware of the issues concerning [native Finnish] revivalist movements and Jehovah's Witnesses but according my understanding also newer Islamist groups entail activities that are not in line with my understanding of human rights, freedom, and equality.

However, even though several comments focused on risks of religiously motivated extremism, some comments also referred to nonreligious forms of extremism, such as far-right nationalist movements (excerpt 34).

[34] I think that [society] should not support any activities that go against Finnish legislation, especially criminal legislation. These include, for example, extremist political and worldview groups. The police should act more severely in forbidding far-right movements from registering as associations.

Also, some comments that raised concerns related to religious extremism pointed out that the best way to oppose these types of movements or actions does not happen through control or restrictions but through education. Examples of these types of viewpoints are expressed in excerpt 35:

[35] The freedom of religion is an important thing and it needs to be cherished. However, it is important to make sure that religious extremist thinking does not spread. This is not, however, achieved by restricting religious freedom but by preventing alienation and providing standard, mainstream religious education.

These types of concerns related to ideological radicalism or extremisms formed a notable orientation towards religion in the data. However, even though these concerns seem to focus on general threats related to extremist thinking, it is notable that the concerns discussed in relation to extremism focus on marginal groups and forms of religious or ideological interpretations. The formulations of issues considered to be threats are broad and show that the respondents, assumedly, are not very familiar with the traditions to which they refer when, for example, they talk about the "The Islamic way of thinking" (excerpt 28). A similar type of distinction between familiar and nonfamiliar traditions was also notable in the fifth orientation titled "Cultural heritage orientation", which is discussed next.

\subsection{Cultural Heritage Orientation}

The approaches identified as belonging to the orientation titled "Cultural heritage orientation" included viewpoints that highlighted the need to cherish Christian traditions as part of Finnish traditions and that were strongly opposed to other forms or worldviews or traditions. The viewpoints could further be divided into orientations that were either mildly accepting of different traditions or that were strongly opposed to the inclusion of 'foreign' traditions in Finland. Examples of milder forms of acceptance are represented in excerpts 36-38, which highlight the importance of maintaining the traditional and historical position of the Evangelical Lutheran Church as the majority of the population are members of this tradition. Whereas the idea represented in excerpt 37 implies that other faiths and worldviews can be respected but not actively supported in Finnish society, the viewpoints presented in excerpt 38 go further in their willingness to find ways to achieve the peaceful co-existence of different religions in Finland.

[36] Finland has always had Christian traditions and these should be respected.

[37] The majority of people in Finland belong to the Evangelical Lutheran church. Even if a person does not belong to this church, our values and ways of acting, our morals, are based on religion. 
Practitioners of other religions need to be respected but it also needs to be remembered what the majority religion in Finland is.

[38] The position of the Evangelical Lutheran and Orthodox churches needs to be protected by the government. Opportunities for practicing the Islamic faith need to be recognized and advanced without disruptions.

However, contrary to these previous viewpoints, some of the respondents showed much stronger or even radically opposed approaches towards the inclusion of non-Christian traditions in Finland. As the following excerpts suggest, the question of religion is associated with questions of nationality and of culture. For example, excerpt 39 refers to Finland as a country that "belongs to Finnish people, not to Bedouins" and excerpt 40 makes a clear separation between Finnish people and Muslims, and thus defines Finland as a non-Muslim country and nation.

[39] In no way. Finland is the land of Finnish people, not Bedouins.

[40] [We should not] support for the faith of Islam. Muslims will populate this country anyway in the long run because of the attractive features it has. Why should anyone support this? Why can't [society] take care of its own people instead of minorities?

Excerpts 41-43 go even further in defining Finnish people, religion, and culture as white and Christian, expressing hostile, even racist, viewpoints about the inclusion or integration of 'foreign' traditions in Finland.

[41] Islamization, that is the place of Islam in politics [should not to be supported]. Building mosques, etc. Letting people wear veils at work, etc. A Religion is everyone's private matter and it should not be practised publicly or at work.

[42] All things concerning the non-white invaders [should not be supported]. Only Christianity in its different forms should be approved.

[43] Money gained from taxes should not be used in any ways to support multiculturalism. We have our own culture that needs to be cherished. There is more than enough expenditure already. They should build their mosques with their own money.

Similar types of viewpoints as these were expressed in several other comments in the data. The findings resemble in many ways the viewpoints mentioned by Casanova (2009) concerning threats associated with the "religious other".

\section{Discussion and Conclusions}

The way in which religion is discussed and problematized in present-day European societies, and especially in education, are topical issues that take many forms. During the last few decades, questions related to certain religions have become increasingly mixed with questions of immigration, security and safety, polarization, and even terrorism (e.g., Gearon 2008, 2018; Davies 2016; Eurobarometer 2018). Whereas the relationship between religious communities and nation-states has changed notably after the modernization process which took place from the mid-19th century onwards, the historical roots and influence of Christianity have been-and continue to be-strong in many European countries (Pérez-Agote 2018; Casanova 2009) and the popularity of immigrant-resistant neonationalism (Eger and Valdez 2015) has increased in many countries.

These changes in society also reflect questions concerning the future of education as they relate to the core values of nationhood, of national and cultural self-understanding, and teaching and learning about different values and worldviews. The education of values needs to start from past experiences (e.g., Bergdahl and Langmann 2018) as well as from the present, so as to prepare for the future. In order to better understand the current situation of values and worldviews in contemporary Finland, this study set out to investigate how politically active young adults experience the role of religion in Finnish society. As a response to the research question, the study identified five main 
themes, or orientations towards the role of religion. These were titled "Positive-neutral orientation", "Negative-neutral orientation", "Secularist orientation", "Security orientation", and "Cultural heritage orientation", representing different viewpoints about the relationship between the state and religion.

Whereas the "Positive-neutral orientation" and "Negative-neutral orientation" orientation titles shared an underlying approach that regarded religions as an acceptable part of society, they differed in their views of the practices that should be taken to advance the equality of religions and differing worldviews in Finnish society. Both approaches can be characterized as secular (see e.g., Taylor 2007) in the way that they subordinated religious practices to the secular legislation of the country. Both of these orientations also aim at the co-existence of various types of worldviews either though positive inclusion of different traditions and customs or by negative neutrality, i.e., creating equality by reducing unfair practices (see also Pierik and van der Burg 2014). On the other hand, the "Secularist orientation" highlighted the need for a fundamental separation of religious institutions and the secular state. These views are in many ways in line with and relatable to the processes of modernization and secularization that have become characteristic not only of Finland but also many other Europe countries (see also Casanova 2009; Pérez-Agote 2018; Taylor 2007).

However, whereas the three previously mentioned orientations make a reasonable continuum for the larger societal and historical process in which the old hegemonic position of religious institutions and new ways regarding religion as a private issue collide, the two other orientation titles, "Security orientation" and "Cultural heritage orientation", seem to highlight new trends of nationalism and even xenophobia (see also Eger and Valdez 2015). In these responses, the concern for religious extremism was mostly attached to traditions that can be described as foreign to the historical Christian and Western understanding of Finnish values and religiosity (see also Casanova 2009). The responses highlighted in these orientations focused on Islam, and especially on minority interpretation of Islam, that were considered a threat on account of their violent character. These kinds of discussions about religions as a threat to security have been increasingly addressed in other countries as well (see e.g., Gearon 2018; Davies 2016). The responses suggest concern about a situation in which the state would not protect its citizens from violent or illegal actions if they were based on religious claims.

The role of education was highlighted in the responses related to all five orientations. The importance of providing knowledge and understanding about different faiths and worldviews was regarded as an important way to combat and reduce prejudices in the "Positive-neutral" orientation that highlighted everyone's freedom to express their worldviews without fear. The importance of education was also mentioned in a few answers in the "Security orientation", pointing out that the best way to combat violent extremism was not through restrictions but education. Likewise, the question of education was central in the "Negative-neutral" approach that called for a change in the current religious and worldview education model in Finland to a system in which all students would be taught the same things and in the same class. Whereas the role of education was not explicitly discussed in the "Cultural heritage orientation" orientation, the ways in which these responses highlight particular traditions as being at the core of Finnish nationhood and as being incompatible with foreign traditions are also in many ways related to questions of education. First, they show the production of a historical way of teaching about Finnishness as a Christian nation, and thus they highlight the critical influence that education, both formal and informal, may have on the self-understanding of a nation and culture. Second, the attitudes represented by these comments show xenophobia and racist characteristics that, even though they are not uncommon (see e.g., Eger and Valdez 2015), are against the educational aims that call for the need to recognize some shared values for peaceful co-existence (e.g., Bergdahl and Langmann 2018) in an interdependent world.

The ways in which the question of religion and worldviews are discussed in society are central questions of values that need, in one form or another, to be addressed in education (e.g., Davies 2016; Quartermaine 2016). Whereas certain measures of security and regulations may be needed in particular cases to prevent the outbreak of violent ideologies, the silencing of people through external rules or force cannot be a sustainable way for democratic societies to govern their people. 
Therefore, the question of how to reduce and decelerate the process of societal polarization is deeply educational in nature (see also Ben-Porath 2012). Related to this, the need to educate people about different worldviews and traditions becomes profoundly important (e.g., Jackson 2016) as well as the need to provide up-to-date knowledge about terrorism (e.g., Malkki and Sallamaa 2018; Gearon 2008). Related to this, it needs to be noted, however, that simply educating about religions does not necessarily lead into an understanding or respectful approach towards different beliefs and worldviews. Likewise, education should not result in a cultural relativist approach in which all claims of values are considered equally good (Bergdahl and Langmann 2018). Instead, education should focus on strengthening the students' critical thinking skills, and media literacy skills that form a core part of the Finnish National Core Curriculum (FNBE 2014).

It can be concluded that the current Finnish curriculum that promotes religious literacy (see also Moore 2015) provides a solid base for teaching and learning about different religions and worldviews in a dialogical, critical, and reflective manner. Having access to academic knowledge about different religions and worldviews is central for developing the competencies needed for recognizing and addressing the values, habits, and customs of these traditions in an intellectual as well as reflective manner (see e.g., FNBE 2014; Ghosh et al., 2017; Moore 2015; Wright 2004). However, the findings of this study also bring forward the strong opinions and fears, and even xenophobic attitudes, that some respondents attached to the national and especially to the religious 'other' (Casanova 2009). These types of findings make it central to ensure that schools are and continue to be places where religions, alongside other worldviews, are discussed openly and in a manner that feels relevant and meaningful for the students (Ghosh 2018). These involve discussing topical issues and concerns related to religions and worldviews, including the possible but not self-evident relationship between violence and religion, as this is central for reducing the fear of the unknown.

For reducing the risk portraying an oversimplified imaginary of an exclusivist Finnish (Christian) identity, it is also important that the historical and contemporary diversity within the Finnish cultural heritage is discussed and represented in educational settings more explicitly than is currently done (see also Niemi forthcoming). Therefore, it is important that Finnish society and education focus on fostering a sense of inclusion that is not based merely on unity over difference but on the sharing of the core values promoted by the Finnish constitution and the Universal Declaration of Human Rights (United Nations 1948). It can be concluded that discussions about the ways in which the society recognizes and supports religions and worldviews is part of the democratic practices needed to keep it inclusive and up to date.

Author Contributions: Conceptualization, P.-M.N., A.K. and R.G. Writing—original draft preparation, P.-M.N., A.K. and R.G.; Writing - review and editing, P.-M.N., A.K. and R.G.

Funding: This research was supported by Alfred Kordelin's Foundation that has granted a working grant to the first author in 2017.

Conflicts of Interest: The authors declare no conflict of interest.

\section{References}

Ben-Porath, Sigal. 2012. Citizenship as Shared Fate: Education for Membership in a Diverse Democracy. Educational Theory 62: 381-95. [CrossRef]

Bergdahl, Lovisa, and Elisabet Langmann. 2018. Time for Values: Responding Educationally to the Call from the Past. Studies in Philosophy and Education 37: 367-82. [CrossRef]

Casanova, Jose. 2009. The Secular and Secularisms. Social Research 76: 1049-66.

Cohen, Louis, Lawrence Manion, and Keith Morrison. 2007. Research Methods in Education, 6th ed. London: Routledge.

Davies, Lynn. 2016. Security, Extremism and Education: Safeguarding or Surveillance? British Journal of Educational Studies 64: 1-19. [CrossRef]

Education Statistics Finland. 2018a. The Number of Students Studying Religions and Secular Ethics in Grades 1-6. Available online: https://vipunen.fi/fi-fi/_layouts/15/xlviewer.aspx?id=/fi-fi/Raportit/Perusopetus\%20\%20ainevalinnat\%20-\%20katsomusaine\%20-\%201-6\%20-\%20maakunta.xlsb (accessed on 8 October 2018). 
Education Statistics Finland. 2018b. The Number of Students Studying Religions and Secular Ethics in Grades 7-9. Available online: https://vipunen.fi/fi-fi/_layouts/15/xlviewer.aspx?id=/fi-fi/Raportit/Perusopetus\%20\%20ainevalinnat\%20-\%20katsomusaine\%20-\%207-9\%20-\%20maakunta.xlsb (accessed on 8 October 2018).

Eger, Maureen A., and Sarah Valdez. 2015. Neo-Nationalism in Western Europe. European Sociological Reviezw 31: 115-30. [CrossRef]

Eurobarometer. 2018. Democracy on the Move: European Elections-One Year to Go. Part II: Complete Survey Results. Available online: http://www.europarl.europa.eu/at-your-service/files/be-heard/ eurobarometer / 2018/ eurobarometer-2018-democracy-on-the-move/top-results / en-one-year-before2019-eurobarometer-results-annex.pdf (accessed on 8 October 2018).

Europol. 2018. EU Terrorism Situation and Trend Report (TE-SAT). Available online: https:/ / www.europol.europa. eu/activities-services / main-reports / european-union-terrorism-situation-and-trend-report-2018-tesat2018 (accessed on 16 January 2019).

Finnish National Board of Education (FNBE). 2004. Finnish National Core Curriculum for Basic Education 2004. Available online: https:/ / www.oph.fi/download/139848_pops_web.pdf (accessed on 10 October 2018). (in Finnish)

Finnish National Board of Education (FNBE). 2014. Finnish National Core Curriculum for Basic Education 2014. Unofficial Translation. Helsinki: FNBE.

Gearon, Liam. 2008. Freedom from Repression: Some Thoughts on Totalitarianism for Religious, Spiritual and Citizenship/Human Rights Education. International Journal of Children's Spirituality 13: 5-14. [CrossRef]

Gearon, Liam. 2015. Education, Security and Intelligence Studies. British Journal of Educational Studies 63: $263-79$. [CrossRef]

Gearon, Liam. 2018. Terrorism and Counter-Terrorism Policy and Research in UK Universities (1997-2017): An Analytic-Structural Review of the Literature and Related Sources. Policy Reviews in Higher Education 2: 32-60. [CrossRef]

Ghosh, Ratna, Alice Chan, Ashley Manuel, Maihemuti Dilimulati, and Mehdi Babaei. 2016. Education and Security: A Global Literature Review on the Role of Education in Countering Violent Religious Extremism. Tony Blair Institute for Global Change. E-publication. Available online: https:/ /institute.global/sites/ default/files/inline-files/IGC_Education\%20and\%20Security.pdf (accessed on 16 January 2019).

Ghosh, Ratna, W. Y. Alice Chan, Ashley Manuel, and Maihemuti Dilimulati. 2017. Can Education Counter Violent Religious Extremism? Canadian Foreign Policy Journal 23: 117-33. [CrossRef]

Ghosh, Ratna. 2018. The Potential of the ERC Program for Combating Violent Extremism among Youth. Religion E Education. [CrossRef]

Itkonen, Tuija, Mirja-Tytti Talib, and Fred Dervin. 2015. 'Not all of us Finns communicate the same way either': Teachers' perceptions of interculturality in upper secondary vocational education and training. Journal of Vocational Education \& Training 67: 397-414. [CrossRef]

Jackson, Robert. 2016. Inclusive Study of Religions and World Views in Schools: Signposts from the Council of Europe. Strasbourg: Council of Europe.

Lynch, Orla. 2013. British Muslim youth: Radicalisation, Terrorism and the Construction of the "Other". Critical Studies on Terrorism 6: 241-61. [CrossRef]

Malkki, Leena, and Daniel Sallamaa. 2018. To Call or Not to Call It Terrorism: Public Debate on Ideologically-motivated Acts of Violence in Finland, 1991-2015. Terrorism and Political Violence 30: 862-81. [CrossRef]

McGoldrick, Dominic. 2011. Religion in the European Public Square and in European Public Life Crucifixes in the Classroom? Human Rights Law Review 11: 451-502. [CrossRef]

Miah, Shamim. 2017. The Muslim problematic: Muslims, State Schools and Security. International Studies in Sociology of Education 26: 138-50. [CrossRef]

Ministry of the Interior. 2017. Annual Report 2017. National Action Plan for the Prevention of Violent Radicalisation and Extremism. Helsinki: Ministry of the Interior Publication, Available online: http:/ /julkaisut.valtioneuvosto. fi/bitstream/handle/10024/80731/SM_24_2017.pdf (accessed on 3 September 2018).

Moore, Diane. 2015. Diminishing religious literacy. In Religious Literacy in Policy and Practice. Part Two. Edited by Adam Dinham and Matthew Francis. Bristol: Policy Press.

Niemi, Pia-Maria. Forthcoming. Religion and Secularity in School Festivals-Experiences and Challenges from Finland. In Contextualising Dialogue, Secularisation and Pluralism: Case Analyses in Finnish Public Education. Edited by Martin Ubani, Inkeri Rissanen and Saila Poulter. Waxmann. 
Niemi, Pia-Maria, Arniika Kuusisto, and Arto Kallioniemi. 2014. Discussing school celebrations from an intercultural perspective-A study in the Finnish context. Intercultural Education 25: 255-68. [CrossRef]

Pérez-Agote, Alfonso. 2018. New Frontiers and Relations between Religion, Culture and Politics in Western Europe. Religions 9: 144. [CrossRef]

Pierik, Roland, and Wibre van der Burg. 2014. What is Neutrality? Ratio Juris 27: 496-515. Available online: https:/ / onlinelibrary.wiley.com/doi/full/10.1111/raju.12057 (accessed on 15 October 2018). [CrossRef]

Quartermaine, Angela. 2016. Discussing Terrorism: A Pupil-Inspired Guide to UK Counter-Terrorism Policy Implementation in Religious Education Classrooms in England. British Journal of Religious Education 38: 13-29. [CrossRef]

Taylor, Charles. 2007. A Secular Age. Cambridge: Harvard University Press.

The Statistics Portal. 2018a. Number of Failed, Foiled or Completed Attacks in the European Union (EU) from 2014 to 2017. Available online: https:/ / www.statista.com/statistics/746562/number-of-arrested-terrorsuspects-in-the-european-union-eu/ (accessed on 15 October 2018).

The Statistics Portal. 2018b. Number of Suspects Arrested for Ethno-Nationalist and Separatist Terrorism in the European Union (EU) from 2012 to 2017. Available online: https://www.statista.com/statistics/746590/ number-of-attacks-of-nationalist-and-separatist-terror-in-the-european-union/ (accessed on 15 October 2018).

The Statistics Portal. 2018c. Number of Suspects Arrested for Religiously Inspired or Jihadist Terrorism in the European Union (EU) from 2012 to 2017. Available online: https:/ / www.statista.com/statistics/746578/ number-of-arrested-terror-suspects-in-the-european-union-eu/ (accessed on 15 October 2018).

United Nations. 1948. Universal Declartion of Human Rights. Available online: http://www.un.org/en/ universal-declaration-human-rights/ (accessed on 10 November 2018).

Wilner, Alex, and Claire-Jehanne Dubouloz. 2010. Homegrown Terrorism and Transformative Learning: An Interdisciplinary Approach to Understanding Radicalization. Global Change, Peace E Security 22: 33-51. [CrossRef]

Wright, Andrew. 2004. Religion, Education, Post-Modernity. London: RoutledgeFalmer.

(C) 2019 by the authors. Licensee MDPI, Basel, Switzerland. This article is an open access article distributed under the terms and conditions of the Creative Commons Attribution (CC BY) license (http:/ / creativecommons.org/licenses/by/4.0/). 